\title{
Complement Activation Reflects Severity of Meconium Aspiration Syndrome in Newborn Pigs
}

\author{
PAAL H.H. LINDENSKOV, ALBERT CASTELLHEIM, GEIR AAMODT, OLA D. SAUGSTAD, AND \\ TOM E. MOLLNES
}

Department of Pediatric Research [P.H.H.L., A.C., O.D.S.], Institute of Immunology [A.C., T.E.M.], and Department of Biostatistics [G.A.], Rikshospitalet University Hospital, N-0027 Oslo, Norway

\begin{abstract}
Meconium aspiration syndrome (MAS) is a serious condition in newborns, associated with a poorly characterized inflammatory reaction. The aim of this study was to investigate a possible role for complement in pulmonary pathophysiology and systemic inflammation in experimental MAS. MAS was induced by instillation of meconium into the lungs of 12 hypoxic piglets. Six controls received saline under otherwise identical conditions. Hemo- and lung dynamics were recorded for $5 \mathrm{~h}$. Plasma complement activation, revealed by the terminal sC5b-9 complex (TCC), and cytokines were measured by enzyme immunoassays. TCC increased substantially in MAS animals compared with controls $(p<0.0005)$. The increase in TCC correlated with lung dysfunction: closely with oxygenation index $(r=0.51, p<$ $0.0001)$ and ventilation index $(r=0.64, p<0.0001)$ and inversely with lung compliance $(r=-0.22, p=0.05)$. IL- $1 \beta$ and tumor necrosis factor- $\alpha$ increased significantly in MAS animals compared with the controls $(p=0.004$ and 0.008 , respectively). The cytokine increase occurred later than TCC and showed correlations with lung dysfunction similar to TCC. IL-10
\end{abstract}

\section{ABSTRACT}

did not discriminate between MAS animals and controls $(p=$ $0.32)$. Finally, the subgroup of MAS animals that died $(n=5)$ had substantially higher TCC concentration compared with the surviving MAS animals $(n=7 ; p<0.0005)$. TCC increased substantially in MAS and was closely correlated to lung dysfunction. Complement activation preceded cytokine release, which may suggest a primary role for complement in the pathophysiology of MAS. (Pediatr Res 56: 810-817, 2004)
$\mathrm{FIO}_{2}$, fraction of inspired oxygen
MAS, meconium aspiration syndrome
MSAF, meconium staining of amniotic fluid
OI, oxygenation index
PIP, peak inspiratory pressure
TCC, terminal sC5b-9 complex
TNF- $\alpha$, tumor necrosis factor- $\alpha$
VI, ventilation index

Meconium staining of amniotic fluid (MSAF) occurs frequently, reported in 5-25\% of all deliveries (1-3), but most infants with MSAF are not affected (1,4-9). Of the minority $(5 \%)$ who develop meconium aspiration syndrome (MAS), $30 \%$ are in need of respiratory support, rendering MAS the most frequent cause for the use of extracorporal membrane oxygenation in the neonatal period (10).

Intrauterine passage of meconium has for centuries been interpreted as a sign of perinatal death or suppression of placental function (7). Since the 1970s, there has been a growing body of evidence suggesting detrimental effects of meconium on newborn lungs, and therapeutic suctioning of the

Received October 30, 2003; Accepted May 4, 2004.

Correspondence: Paal H.H. Lindenskov, M.D., Department of Pediatric Research (PFI), Rikshospitalet University Hospital, N-0027 Oslo, Norway; e-mail: p.h.h. lindenskov@klinmed.uio.no

The study was financially supported by The Research Council of Norway (research fellowship for P.H.H.L.); The Norwegian Foundation for Health and Rehabilitation; Research Council of Rikshospitalet; and Tanox, Inc. (Houston, TX).

DOI: 10.1203/01.PDR.0000141983.32466.2A airways to clear meconium therefore was established routinely $(11,12)$. Intratracheal suction should be performed only in selective cases (13). The role of meconium per se in the pathophysiology of MAS is still debated (14) and has been questioned by Katz and Bowes (4), claiming that antenatal asphyxia leading to persistent pulmonary hypertension could cause the lung injury, leaving a minor role to direct effects mediated by meconium.

In clinical medicine, the diversity between MSAF and MAS may be due to several meconium-related factors, such as different amounts being aspirated (15), composition (16-18) and consistency (19) of meconium, intrauterine effects of meconium $(4,20)$, and severity and duration of accompanying asphyxia (4). In the experimental model used in the present study (21), most of these factors can be standardized. Still, in previous experiments using the same model with higher doses of meconium, we have observed a substantial interanimal variation in morbidity and mortality, leading us to speculate that various host factors could be related to the severity of the inflammation triggered by meconium. 
Inflammation is important in the pathogenesis of MAS, but the extent of data permitting explanation for the inflammatory reactions at a molecular level are still limited. Meconium was found to increase the production of eicosanoids via phospholipase $A_{2}$ (18), to stimulate production of tumor necrosis factor- $\alpha(\mathrm{TNF}-\alpha)$ (22), and to increase the expression of intracellular adhesion molecule-1 (23). Furthermore, meconium may both inhibit (24) and stimulate phagocytosis $(23,24)$ and stimulate chemotaxis, the latter effect claimed to be due to IL-8 present in meconium (25). Two reports on meconiuminduced oxidative burst are contradictory $(24,26)$.

Complement is part of the innate immune system and plays an important role in inflammation and tissue damage in various pathophysiologic conditions (27). We recently observed that meconium is a potent activator of the alternative complement pathway in vitro (28). In the present study, we aimed to investigate the role of complement activation in experimental MAS, with emphasis on its relation to morbidity and its possible role in MAS-induced inflammation.

\section{METHODS}

Animals. Norwegian Domestic race piglets, maximum $2 \mathrm{~d}$ old, were selected at two farms by two farmers and delivered on the day of experiment. Their weight range was $1.6-2.3 \mathrm{~kg}$ $(1.8 \pm 0.1)$. Exclusion criteria were weight $<1200 \mathrm{~g}, \mathrm{Hb}<5$ $\mathrm{g} / \mathrm{dL}$, oxygen saturation $<90 \%$ in room air, hypoxia time $<30$ min, or death within $30 \mathrm{~min}$ of reoxygenation. Two animals were excluded in accordance with the death criterion. Five of the 12 animals of the MAS group died after 30 min of reoxygenation and were included in the study. They died at the following time points: 105, 129, 168, 233, and $245 \mathrm{~min}$ of reoxygenation, respectively. Physiologic data for MAS and control animals are shown in Table 1. There was no difference in physiologic markers between the two groups of animals before instillation of meconium, and the weight was equal in the two groups.
Anesthesia and surgery. Anesthesia induction was by 5\% halothane in an equal mixture of air and oxygen $(3+3 \mathrm{~L})$ until sleep and thereafter reduced to a maintenance level of $1-2 \%$. The piglets were tracheotomized in supine position with infiltration anesthesia (lidocaine $10 \mathrm{mg} / \mathrm{mL}$, maximum $7 \mathrm{mg} / \mathrm{kg}$ ). Furthermore, the piglets were ventilated (Laerdal silicone resuscitation bag, infant size; Laerdal, Stavanger, Norway) through an uncuffed endotracheal tube (inner diameter $3.5 \mathrm{~mm}$; Portex Ltd Hythe, Kent, UK) while boluses of pentobarbital sodium (20 mg/kg), fentanyl (50 $\mu \mathrm{g} / \mathrm{kg})$, and pancuronium $(0.4$ $\mathrm{mg} / \mathrm{kg}$ ) were injected intravenously. For the rest of the experiment, the piglets, in the supine position, were connected to a ventilator (Dräger Babylog 8000 plus, Lübeck, Germany) except for the first $30 \mathrm{~s}$ of reoxygenation. I.v. anesthesia (fentanyl $50 \mu \mathrm{g} \cdot \mathrm{kg}^{-1} \cdot \mathrm{h}^{-1}, 25 \mu \mathrm{g} \cdot \mathrm{kg}^{-1} \cdot \mathrm{h}^{-1}$ during hypoxia, and midazolam $250 \mu \mathrm{g} \cdot \mathrm{kg}^{-1} \cdot \mathrm{h}^{-1}, 125 \mu \mathrm{g} \cdot \mathrm{kg}^{-1} \cdot \mathrm{h}^{-1}$ during hypoxia) was given for the rest of the experiment by syringe pumps (IVAC P 2000, Basingstoke, UK, and TERUMO STC521, Tokyo, Japan) through the femoral vein. Pancuronium was given as intermittent boluses $(0.01 \mathrm{mg} / \mathrm{kg})$. Volume therapy was by $6 \mathrm{~mL} \cdot \mathrm{kg}^{-1} \cdot \mathrm{h}^{-1}$ combined saline-glucose infusion. The urinary bladder was emptied by suprapubic aspiration. For monitoring mean artery blood pressure and central venous pressure, polythene catheters (nonsterilized, siliconized, Portex PE-50, inner diameter $0.58 \mathrm{~mm}$, outer diameter 0.96 mm, ref 800/110/200; Portex, Hythe, Kent, UK) were inserted in the femoral arteries and external jugular vein. By means of pressure transducers (Edwards Life Science, Hina, Dominican Republic), hemodynamic data were collected in a computer system (Model MP 100; Biopac Systems, Inc., Santa Barbara, CA).

Meconium. Samples of meconium from 58 healthy newborns were harvested from diapers with a wooden-spatula and collected in 50-mL polypropylene centrifuge tubes (Corning Inc., Acton, MA) and kept at $-20^{\circ} \mathrm{C}$. The samples were thawed, pooled, and processed by a hand blender (Bosch MSM

Table 1. Physiologic data of MAS piglets and controls during the course of the experiment

\begin{tabular}{|c|c|c|c|c|c|c|c|c|}
\hline Group & Stab & $\mathrm{H} 20$ & R20 & R1h & $\mathrm{R} 2 \mathrm{~h}$ & $\mathrm{R} 3 \mathrm{~h}$ & $\mathrm{R} 4 \mathrm{~h}$ & R5h \\
\hline \multicolumn{9}{|l|}{ MABP $(\mathrm{mmHg})$} \\
\hline MAS & $81 \pm 3$ & $60 \pm 4$ & $68 \pm 3$ & $57 \pm 3$ & $50 \pm 4$ & $52 \pm 5$ & $55 \pm 6$ & $59 \pm 4$ \\
\hline Control & $81 \pm 7$ & $49 \pm 7$ & $61 \pm 9$ & $65 \pm 8$ & $65 \pm 8$ & $57 \pm 9$ & $59 \pm 8$ & $61 \pm 6$ \\
\hline MAS & $7.52 \pm 0.02$ & $7.33 \pm 0.03$ & $7.14 \pm 0.02$ & $7.27 \pm 0.02$ & $7.28 \pm 0.06$ & $7.33 \pm 0.06$ & $7.34 \pm 0.10$ & $7.40 \pm 0.04$ \\
\hline Control & $7.54 \pm 0.03$ & $7.37 \pm 0.06$ & $7.25 \pm 0.03$ & $7.38 \pm 0.02$ & $7.43 \pm 0.03$ & $7.46 \pm 0.03$ & $7.49 \pm 0.03$ & $7.47 \pm 0.03$ \\
\hline \multicolumn{9}{|l|}{$\mathrm{BE}$} \\
\hline \multicolumn{9}{|l|}{$\mathrm{PaCO}_{2}(\mathrm{kPa})$} \\
\hline MAS & $4.2 \pm 0.2$ & $4.3 \pm 0.1$ & $4.0 \pm 0.2$ & $5.0 \pm 0.2$ & $5.2 \pm 0.2$ & $5.0 \pm 0.3$ & $4.6 \pm 0.3$ & $4.9 \pm 0.23$ \\
\hline Control & $4.1 \pm 0.2$ & $4.2 \pm 0.2$ & $3.6 \pm 0.1$ & $4.2 \pm 0.2$ & $4.9 \pm 0.4$ & $4.8 \pm 0.3$ & $4.5 \pm 0.14$ & $4.8 \pm 0.19$ \\
\hline \multicolumn{9}{|l|}{$\mathrm{PaO}_{2}(\mathrm{kPa})$} \\
\hline MAS & $10.7 \pm 0.4$ & $3.9 \pm 0.8$ & $13.8 \pm 3.4$ & $9.1 \pm 0.6$ & $8.6 \pm 0.7$ & $9.6 \pm 0.7$ & $10.0 \pm 0.9$ & $9.0 \pm 0.8$ \\
\hline Control & $11.1 \pm 0.6$ & $3.2 \pm 0.1$ & $14.2 \pm 1.4$ & $10.8 \pm 0.5$ & $10.3 \pm 0.9$ & $10.2 \pm 0.9$ & $10.9 \pm 0.8$ & $9.7 \pm 0.6$ \\
\hline
\end{tabular}

Data are mean \pm SEM

Stab, stabilization; H20, 20 min after hypoxia; R20, 20 min after reoxygenation; R1h-R5h, 1-5 h after reoxygenation; MABP, mean arterial blood pressure; $\mathrm{BE}$, base excess; $\mathrm{PaCO}_{2}$, arterial partial pressure of carbon dioxide; $\mathrm{PaO}_{2}$, arterial partial pressure of oxygen; $\mathrm{V}_{\mathrm{T}}$, tidal volume. 
4001/01, Nazarje, Slovenia) in physiologic saline until the mixture was homogeneous. The batch was then freeze-dried and irradiated to secure sterility ( $\gamma$-rays, $32 \mathrm{kGy}$; Institute for Energy Technology, Kjeller, Norway). There was no bacterial growth in the batch. Finally, the preparation was reconstituted with saline to a weight concentration of $135 \mathrm{mg} / \mathrm{mL}$ and frozen in aliquots at $-20^{\circ} \mathrm{C}$ until the day of the experiment.

Experimental model. After completion of surgery, a 30-min stabilization period, and a subsequent hypoxic period, the animals were randomized by drawing lots during hypoxia for either instillation of meconium $(675 \mathrm{mg} / \mathrm{kg}$; i.e. $5 \mathrm{~mL} / \mathrm{kg}$ of a preparation that contained $135 \mathrm{mg} / \mathrm{mL} ; n=12)$ or an equal volume of physiologic saline $(n=6)$ into the lungs. Hypoxia was induced by breathing $8 \%$ oxygen in nitrogen (AGA, Oslo, Norway) and maintained until base excess was $\leq-20 \mathrm{mM}$ $(-21.5 \pm 0.6)$. After instillation of meconium, the piglets were manually ventilated 30 times in ambient air with the rate $1 / \mathrm{s}$ with an insufflation pressure securing visually adequate chest expansion. Subsequently, they were connected to the ventilator after increasing the settings: rate from 30 to $60 / \mathrm{min}$, the peak inspiratory pressure (PIP) $5 \mathrm{~cm} \mathrm{H}_{2} \mathrm{O}$ beyond the preceding PIP, and the fraction of inspired oxygen $\left(\mathrm{FIO}_{2}\right)$ from 8 to $21 \%$. All of these adjustments were for the first $10 \mathrm{~min}$ of the reoxygenation period. Later, the ventilator settings were adjusted as needed to keep oxygen saturation $>85 \%$ and arterial partial pressure of carbon dioxide in the range 4-6 $\mathrm{kPa}$. Maximum settings were rate 60/min, $\mathrm{FiO}_{2} 0.90$, and PIP $45 \mathrm{~cm} \mathrm{H}_{2} \mathrm{O}$. Lung function was monitored by the ventilator. Mean airway pressure was measured at the Y-piece, and lung volumes were calculated as a function of flow. Dynamic lung compliance $\left(\mathrm{C}_{\mathrm{dyn}} ; \mathrm{mL} / \mathrm{mbar}\right.$ ) was calculated by a computer program (Software 5.n; Drägerwerk AG, Lübeck, Germany) integrated in the ventilator. Oxygenation index (OI) was calculated according to the following formula: $\mathrm{OI}=\left(\right.$ mean airway pressure $\left.\times \mathrm{FiO}_{2}\right) /$ arterial oxygen pressure $\times$ 7.5. Ventilation index (VI) was calculated according to the following formula: VI $=$ (arterial partial pressure of carbon dioxide $\times 7.5 \times \mathrm{F} \times \mathrm{PIP}) / 1000$, where $\mathrm{F}$ is ventilation frequency/min.

Blood sampling. Blood was collected from the femoral artery on eight occasions (baseline, $20 \mathrm{~min}$ after start of hypoxia, and $20 \mathrm{~min}$ and $1,2,3,4$, and $5 \mathrm{~h}$ after start of reoxygenation) in $0.7-\mathrm{mL}$ portions into EDTA tubes, immediately cooled in ice, and spun at $1500 \times g$ for $15 \mathrm{~min}$ at $4^{\circ} \mathrm{C}$. The supernatants were immediately stored at $-70^{\circ} \mathrm{C}$ until analyzed in batch. Arterial blood gas tensions and base excess were determined on $0.2-\mathrm{mL}$ samples withdrawn from the femoral artery (Ciba-Corning Bloodgas analyser 860, Medfield, MA). The catheters in the femoral arteries were continuously flushed with heparin $(6 \mathrm{IU} / \mathrm{h})$. The $\mathrm{Hb}$ level was measured at the start and at the end of the experiment (CibaCorning 279 Co-oximeter). The total withdrawal $(<10 \mathrm{~mL})$ corresponded to $<10 \%$ of the total blood volume.

Complement activation. Porcine terminal sC5b-9 complex (TCC) was quantified by an enzyme immunoassay using the MAb aE11, which cross-reacts with pig (29) as capture antibody diluted in PBS and incubated in microtiter plates (COSTAR EIA plate 3590; Corning, Inc., New York, NY) overnight (50 $\mu \mathrm{L} /$ well). As standard, zymosan-activated hu- man serum was made by incubation of $10 \mathrm{mg}$ of zymosan (Sigma, St. Louis, MO) per $\mathrm{mL}$ of a serum pool $(n=10)$ for $1 \mathrm{~h}$ at $37^{\circ} \mathrm{C}$. The standard was defined to contain 1000 arbitrary units $(\mathrm{AU}) / \mathrm{mL}$ and was applied as a standard curve diluted 2-fold in six steps with $2.5 \mathrm{AU} / \mathrm{mL}$ as the highest standard. The porcine plasma samples were diluted 1:4. Both standard and samples were diluted in PBS that contained $0.2 \%$ azide, $0.2 \%$ Tween 20, and $20 \mathrm{mM}$ EDTA and incubated for $60 \mathrm{~min}$ at $4^{\circ} \mathrm{C}$ (50 $\mu \mathrm{L} /$ well). Detection antibody was a biotinylated monoclonal anti-human C6 cross-reacting with pig (Quidel, San Diego, CA), diluted in PBS that contained $0.2 \%$ Tween 20, and incubated for $60 \mathrm{~min}$ at $37^{\circ} \mathrm{C}(50 \mu \mathrm{L} /$ well $)$. Streptavidinhorseradish peroxidase (RPN1231V; Amersham Biosciences Europe $\mathrm{GmbH}$, Freiburg, Germany), diluted 1:400, was then added and incubated for $60 \mathrm{~min}$ in $37^{\circ} \mathrm{C}(50 \mu \mathrm{L} / \mathrm{well})$. Finally, substrate solution was added (100 $\mu \mathrm{L} /$ well): $0.003 \% \mathrm{H}_{2} \mathrm{O}_{2}$ in $0.33 \mathrm{mM}$ of 2,2 azino-di(3-ethyl)-benzthiazoline sulfonate (Roche Diagnostics GmbH, Mannheim, Germany) in $0.1 \mathrm{M}$ of Na-acetate buffer ( $\mathrm{pH} 4.0$ ), incubated at room temperature for 15 min before stop solution ( $2 \mathrm{~N}$ of $\mathrm{H}_{2} \mathrm{SO}_{4}$ ) was added (100 $\mu \mathrm{L} /$ well). Between each incubation, the plates were washed thrice with PBS that contained $0.1 \%$ Tween 20. OD was read at $405 \mathrm{~nm}$ using $490 \mathrm{~nm}$ as reference (MRX microplate reader; Dynex Technologies, Denkendorf, Germany).

Cytokines and soluble adhesion molecules. Commercially available enzyme immunoassays were performed according to the instructions from the manufacturer for the following markers: IL- $1 \beta$ (R\&D Systems, Oxford, UK), TNF- $\alpha$ (R\&D Systems), IL-10 (Bio Source/Med Probe, Camarillo, CA), IL-8 (Bio Source/Med Probe), sTNF-R (Bender/AH Diagnostics, Vienna, Austria), $\gamma$-interferon (Bio Source/Med Probe), sVCAM-1 (Bender/AH Diagnostics), sP-selectin (Bender/AH Diagnostics), and sVE-cadherin (Bender/AH Diagnostics). Only IL- $1 \beta$, TNF- $\alpha$, and IL-10 showed detectable levels in the piglet plasma samples and are discussed further. The remaining markers were undetectable either because of lack of sensitivity of the assay (many of which were human assays indicated to have some cross-reactivity to pig) or because they were not synthesized within the observation period.

Statistics. Data are shown as mean values and SEM. Delta values were used to eliminate differences between animals at baseline, and in these cases, the data are presented as percentage change from baseline. Variables that did not show normal distribution were $\log$ transformed. ANOVAs were used to compare groups (Bonferroni correction was chosen as post hoc test). This statistical method accommodates missing data (e.g. death of piglets during the observation time). Pearson correlation coefficients were estimated to model the linear relationship between variables. Rejection probability in hypothesis testing was set to $5 \%$.

Ethics. The experimental protocol was approved by The Norwegian Animal Experimental Board.

\section{RESULTS}

\section{Pulmonary Pathophysiology}

Lung function evaluated by OI, VI, and lung compliance deteriorated substantially in MAS animals compared with the 
controls $(p<0.0005$ for all; Fig. 1). OI (Fig. 1, top) increased in MAS animals from $1.5 \pm 0.1$ (mean \pm SEM) to $9.8 \pm 1.2$ (mean \pm SEM for all time points after instillation of meconium) and in the controls from $1.5 \pm 0.1$ to $2.1 \pm 0.1$. VI (Fig. 1, middle) increased in MAS animals from $17.3 \pm 1.8$ to 51.4 \pm 2.8 and in the controls from $19.2 \pm 1.6$ to $25.3 \pm 1.2$. Lung compliance (Fig. 1, bottom) decreased in MAS animals from $2.2 \pm 0.1$ to $1.2 \pm 0.04$ and in the controls from $2.2 \pm 0.2$ to $1.8 \pm 0.1$. There was no statistically significant difference in tidal volumes between MAS animals $(13.3 \pm 0.4 \mathrm{~mL} / \mathrm{kg}$; mean \pm SEM for all time points after instillation of meconium) and controls $(13.8 \pm 0.25 \mathrm{~mL} / \mathrm{kg} ; p=0.65)$.

\section{Complement Activation}

Complement activation measured as TCC was significantly higher in MAS animals compared with the controls $(p<$

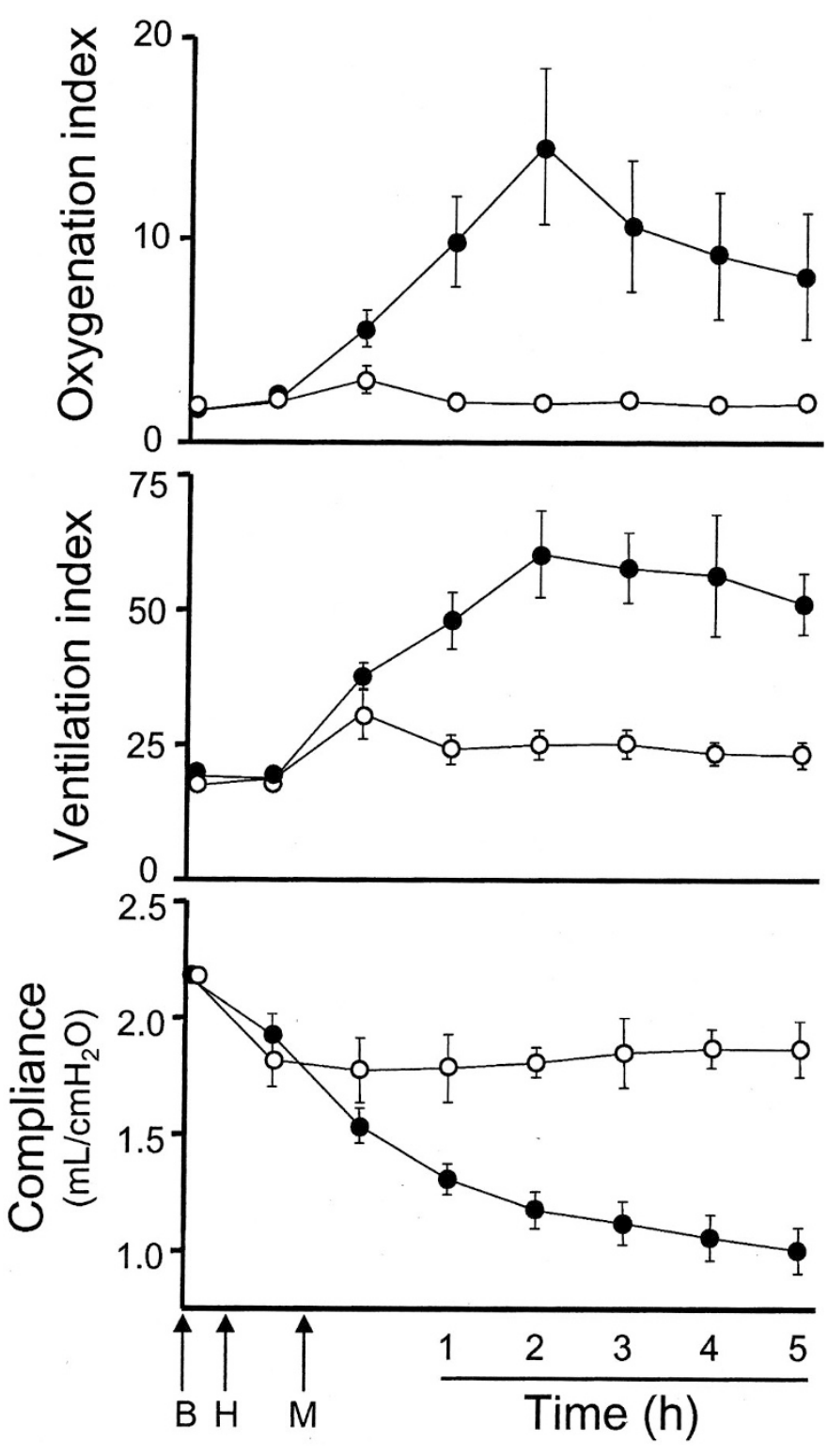

Figure 1. Pathophysiology. OI (top), VI (middle), and lung compliance (bottom) during the course of control animals' receiving saline $(n=6 ; \bigcirc)$ and MAS animals' receiving meconium $(n=12$; $)$. MAS animals $v$ controls: $p$ $<0.0005$ for all. B, baseline; $\mathrm{H}$, hypoxia; $\mathrm{M}$, instillation of meconium.
0.0005; Fig. 2, top). TCC increased in MAS animals by $82 \pm$ $34 \%$ (mean \pm SEM for all time points after instillation of meconium) compared with a decrease in the controls $(-37 \pm$ $0.1 \%$ ); the latter was consistent with the hemodilution observed in all animals. TCC correlated closely with lung dysfunction: positively with OI $(r=0.51 ; p<0.0001$; Fig. 3, top $)$ and VI ( $r=0.64 ; p<0.0001$; Fig. 3, middle $)$ and negatively with lung compliance $(r=-0.22 ; p=0.05$; Fig. 3, bottom $)$.

\section{Cytokines}

IL- $1 \beta$ increased in MAS animals from $18.0 \pm 1.9$ to 101.5 $\pm 30.0 \mathrm{pg} / \mathrm{mL}$ (mean \pm SEM for all time points after instil-

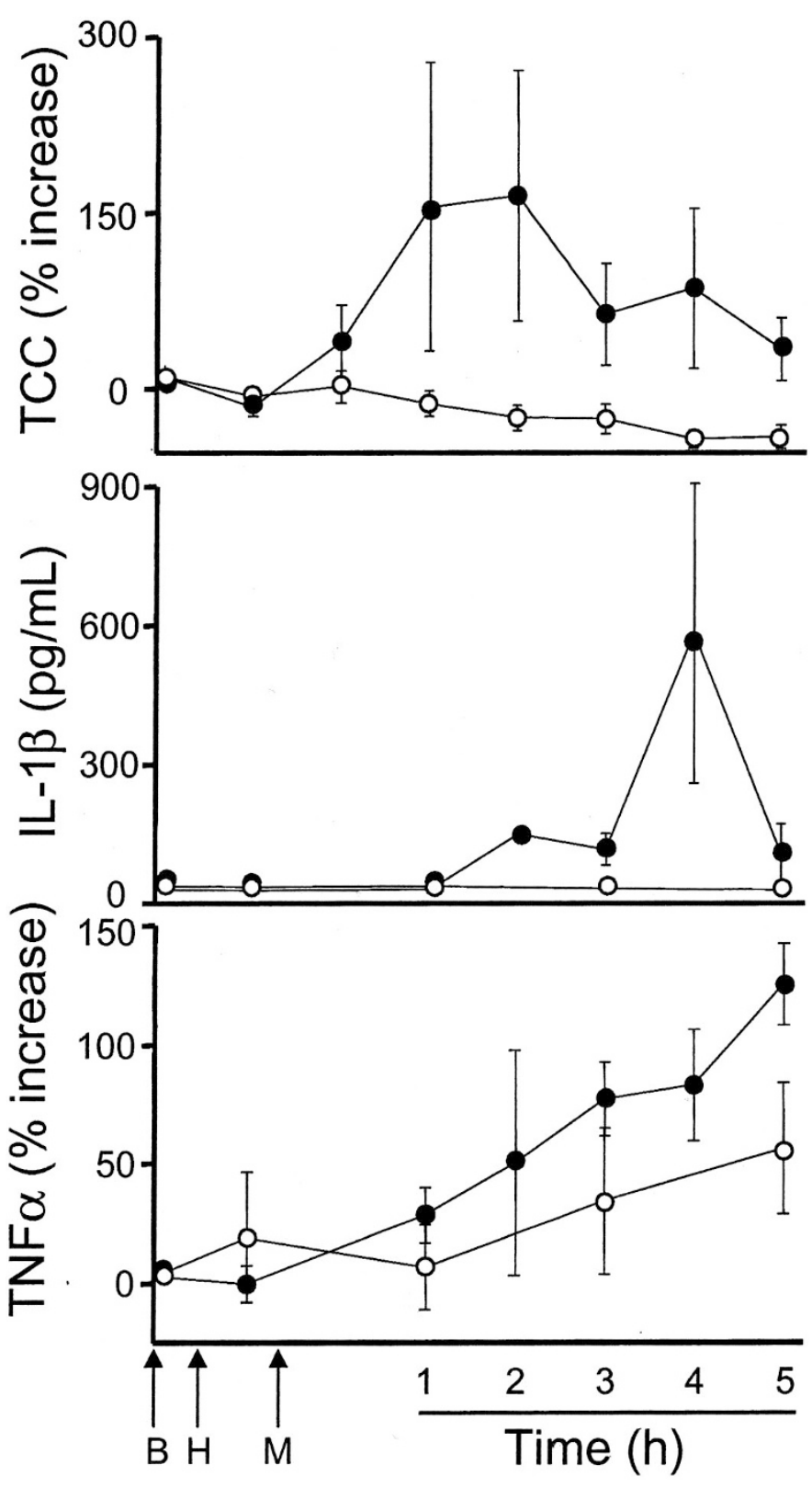

Figure 2. Complement activation and cytokine release. The TCC (top), IL-1 $\beta$ (middle), and TNF- $\alpha$ (bottom) during the course of control animals' receiving saline $(n=6 ; \bigcirc)$ and MAS animals' receiving meconium $(n=12 ; \bullet)$. Percentage changes from baseline are indicated for TCC and TNF- $\alpha$ because baseline values differed between the groups for these markers. MAS vs controls: TCC, $p<0.0005$; IL- $1 \beta, p=0.004$; and TNF- $\alpha, p=0.008$. B, baseline; $\mathrm{H}$, hypoxia; $\mathrm{M}$, instillation of meconium. 

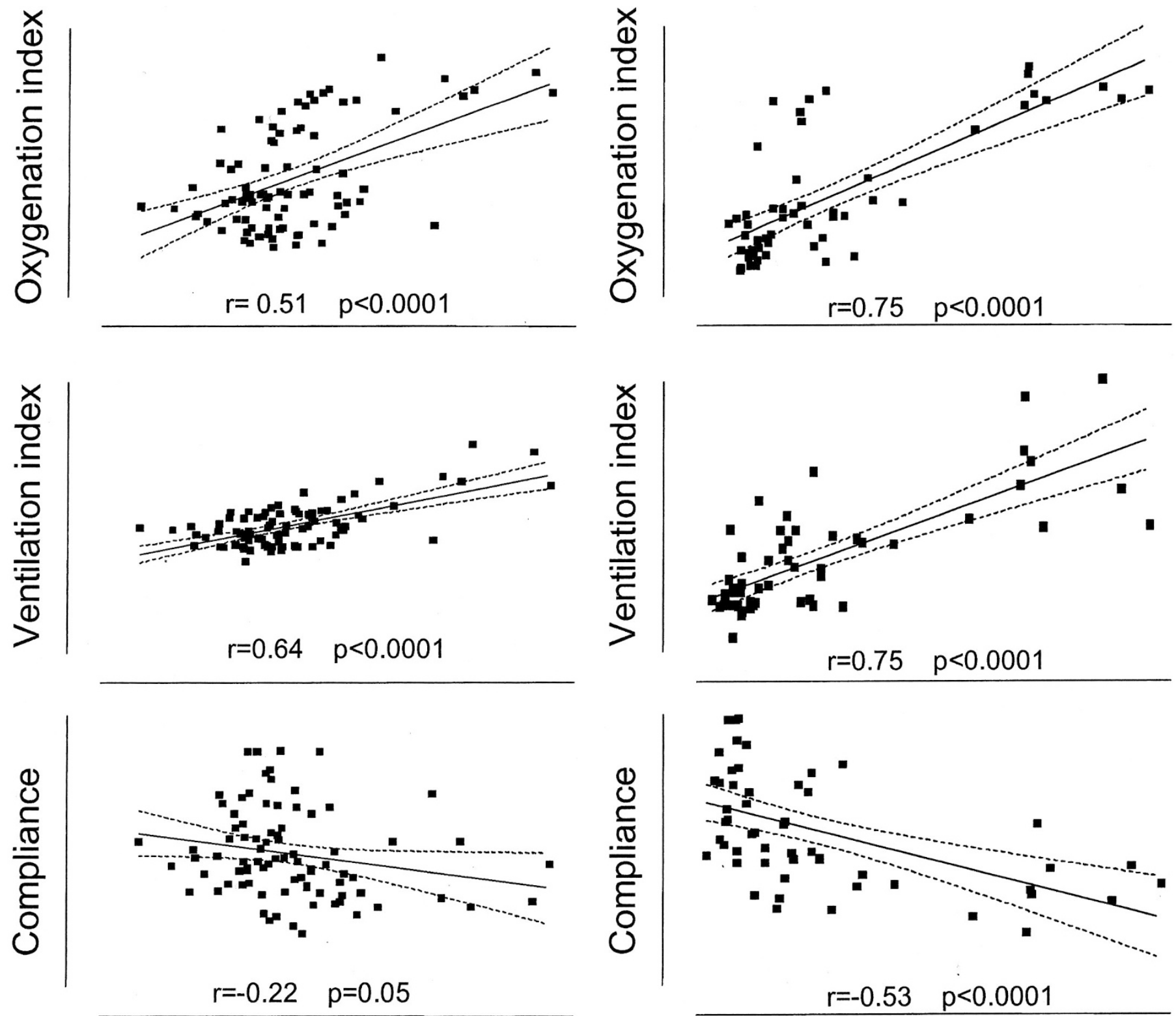

\section{Complement activation (TCC)}

Figure 3. Complement activation and pulmonary function. Correlation between complement activation (TCC) and lung function in the animal group that received meconium. (Top) Correlation between TCC and OI. (Middle) Correlation between TCC and VI. (Bottom) Correlation between TCC and lung compliance.

lation of meconium), whereas no change was observed in the controls $(23.5 \pm 7.3$ to $21.7 \pm 2.9 \mathrm{pg} / \mathrm{mL} ; p=0.004$ MAS versus controls). IL-1 $\beta$ correlated closely with lung dysfunction: positively with OI $(r=0.75 ; p<0.0001$; Fig. 4 , top $)$ and VI $(r=0.75 ; p<0.0001 ;$ Fig. 4 , middle $)$ and negatively with lung compliance $(r=-0.53 ; p<0.0001$; Fig. 4, bottom). IL-1 $\beta$ correlated closely with TCC $3 \mathrm{~h}$ after instillation of meconium $(r=0.69, p=0.004)$.

TNF- $\alpha$ increased in MAS animals by $72 \pm 10 \%$ (mean \pm SEM for all time points after instillation of meconium) compared with $34 \pm 16 \%$ in the controls $(p=0.008$ MAS versus controls). TNF- $\alpha$ correlated closely with lung dysfunction:

positively with OI $(r=0.44 ; p=0,004 ;$ Fig. 5 , top $)$ and VI $(r$ $=0.55 ; p=0.0001$; Fig. 5 , middle $)$ and negatively with lung compliance $(r=-0.59 ; p<0.0001$; Fig. 5 , bottom). IL-10 increased in MAS animals from $1.5 \pm 0.1$ to $8.8 \pm 4.1 \mathrm{pg} / \mathrm{mL}$ (mean \pm SEM for all time points after instillation of meconium) and from $2.0 \pm 0.6$ to $3.8 \pm 0.8 \mathrm{pg} / \mathrm{mL}$ in controls $(p=$ 0.32 MAS versus controls).

\section{Subgroups of Dead and Surviving MAS Animals}

Pathophysiology. Five of the 12 MAS animals died during the observation period, whereas all controls survived. OI increased substantially more from $1.5 \pm 0.04$ to $18.8 \pm 2.4$ in the 

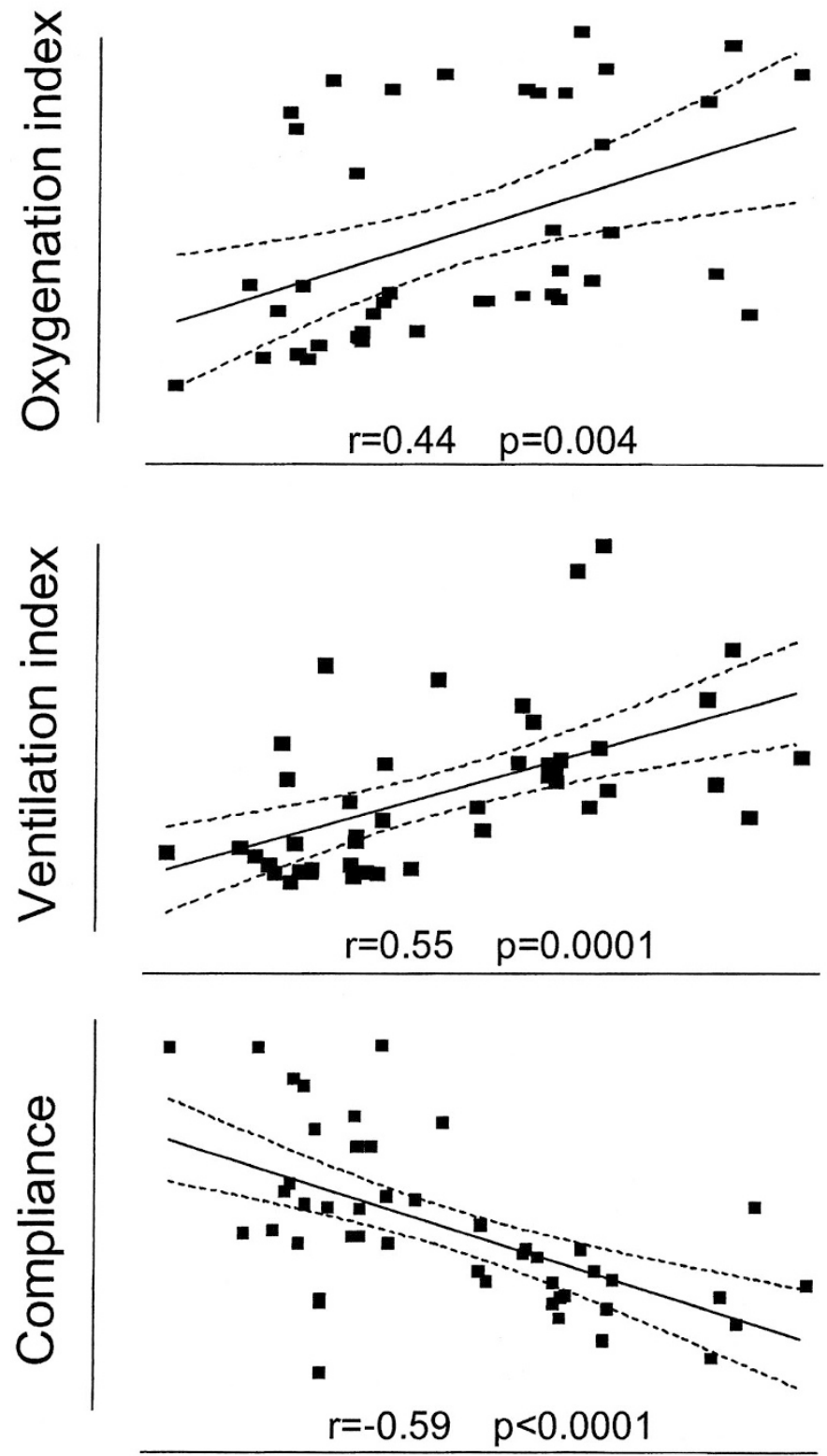

TNF $\alpha$

Figure 5. TNF- $\alpha$ and pulmonary function. Correlation between TNF- $\alpha$ and lung function in the animal group that received meconium. (Top) Correlation between TNF- $\alpha$ and OI. (Middle) Correlation between TNF- $\alpha$ and VI. (Bottom) Correlation between TNF- $\alpha$ and dynamic lung compliance.

subgroup of MAS animals that died compared with surviving MAS animals $(1.6 \pm 0.09$ to $5.9 \pm 0.8 ; p<0.0005$; Fig. 6 , top). Similar significant differences were seen for VI and lung compliance between MAS animals that died and those that survived (data not shown).

Complement activation. Notably, a most extensive difference in TCC increase was observed between MAS animals with fatal outcome (265 $\pm 90 \%)$ compared with survivors with MAS $(-5.9 \pm 0.1 \%)$, with no overlap between TCC values in the two groups ( $p<0.0005$; Fig. 6, bottom).

Cytokines. MAS animals with fatal outcome had a significantly higher increase in IL- $1 \beta(16.1 \pm 1.2$ to $181.8 \pm 72.6$ $\mathrm{pg} / \mathrm{mL})$ compared with survivors with MAS $(17.7 \pm 0.9$ to
Controls MAS survived MAS dead

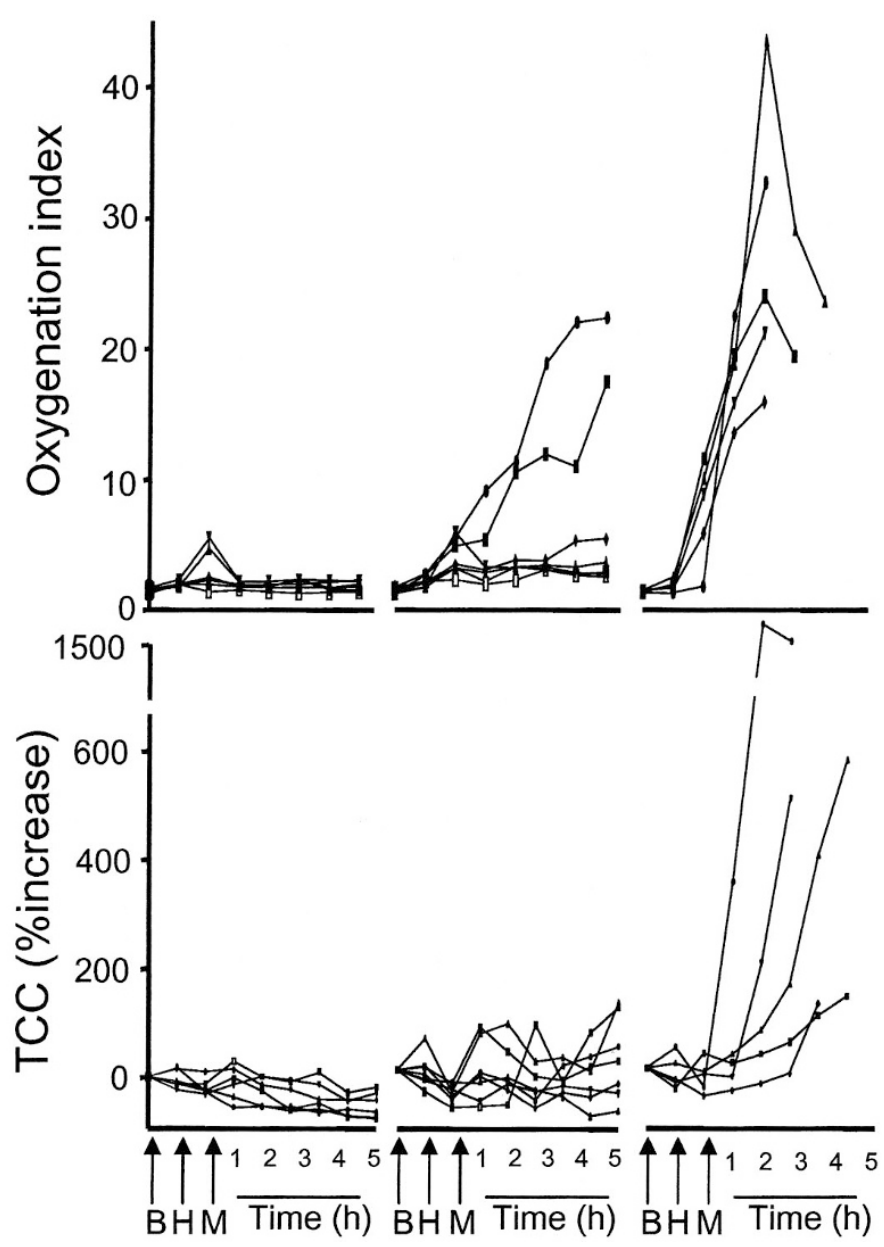

Figure 6. Subgroup analysis of mortality. The MAS group was divided into survivors $(n=7)$ and nonsurvivors $(n=5)$ and compared with respect to OI (top) and TCC (bottom). The control group $(n=6)$ is shown to the left for comparison. The differences in OI and TCC was highly significant between the two MAS subgroups $(p<0.0005)$.

$55.6 \pm 8.9 \mathrm{pg} / \mathrm{mL} ; p=0.006)$. TNF- $\alpha$ increased by $55 \pm 17 \%$ in MAS animals with fatal outcome and by $83 \pm 13 \%$ in surviving MAS animals, without any significant difference between the groups.

\section{DISCUSSION}

In previous experimental MAS, we have observed a substantial interanimal variation in morbidity and mortality, leading us to speculate that various host factors could be related to the severity of the inflammation triggered by meconium. In the present study, we found that meconium activated complement measured by TCC in piglets. Complement activation was substantially more pronounced in MAS animals compared with control animals, which received saline instillation instead of meconium. Furthermore, complement activation correlated closely to deterioration of lung function as measured by OI, VI, and lung compliance. IL- $1 \beta$ displayed a similar pattern as TCC but with some time latency. These data suggest that complement activation is an early and important event in the patho- 
physiology of MAS, followed by other inflammatory reactions, such as release of cytokines.

As part of the innate immune system, complement is important in inflammation (27). Activation of the complement cascade induces formation of inflammatory mediators such as the anaphylatoxin $\mathrm{C} 5 \mathrm{a}$, which stimulates inflammatory cells to produce cytokines, arachidonic acid metabolites, and reactive oxygen metabolites. However, various inflammatory mediators may induce complement activation; thus, a complex mutual interaction between complement and other arms of the inflammatory network occurs. In vitro, meconium may directly increase activity of phospholipase $A_{2}$ (18), which catalyze formation of eicosanoids. Release of eicosanoids probably may reinforce the complement-induced induction of proinflammatory arachidonic acids. Similar mechanisms may be operative for oxygen radicals and cytokines as meconium stimulates macrophage production of TNF- $\alpha$ (22) and superoxide anion (23).

As a preformed protein cascade, the complement system, in contrast to cytokines that need to be synthesized, is activated without latency, e.g. by exposure to foreign material, physical trauma, and ischemia (30). This raises the possibility that complement might be activated as a result of procedures related to anesthesia, surgery, and hypoxia-induced stress in this model. The absence of complement activation in the control animals, however, rules out this possibility because these animals were treated exactly in the same manner as the MAS animals, except for instillation of meconium. Furthermore, no differences were observed in weight or physiologic markers between the groups before instillation of meconium and saline, respectively. Ventilatory support may cause inflammatory lung injury as a result of volutrauma, barotrauma, or oxygen toxicity (31). In our study, however, there was no statistically significant difference in tidal volumes between MAS animals and controls. Despite relatively high tidal volumes, no increase in TCC or IL- $1 \beta$ was found in the control animals, indicating that meconium per se induced the inflammatory reaction, consistent with the in vitro observation that meconium is a potent activator of complement (28). It cannot be excluded, however, that meconium-induced lung dysfunction with surfactant inactivation, local acidosis, and hypoxia may enhance the meconium-induced complement activation.

It is commonly held that lung inflammation is essential in the pathogenesis of MAS, but the documentation thereof is still limited, and most of the studies have been performed in vitro. No previous studies have documented a relation between complement activation and severity of experimental MAS. We recently documented, however, that human meconium is a potent activator of the alternative complement pathway in human adult and cord serum (28). The present study lends further support to the hypothesis that meconium-induced complement activation may be of importance in the development of clinical MAS.

In vivo infiltration of neutrophils has been shown in experimental MAS in humans and piglets $(1,32)$. Favorable effects of glucocorticoids have been documented in lungs $6 \mathrm{~h}$ after instillation of meconium $(33,34)$. Increased neutrophil counts and chemotactic activity have been shown in tracheal aspirates from piglets $12 \mathrm{~h}$ after instillation of meconium (35). Recently, we found an increase in the potent chemotactic factor IL-8 in tracheal aspirates within $8 \mathrm{~h}$ after instillation of meconium in hypoxic piglets (36). Along with IL-8, the complement activation product $\mathrm{C} 5 \mathrm{a}$ is one of the most potent chemotactic factors released during inflammation. We have measured complement activation by formation of TCC, the final product of the terminal pathway. Formation of TCC is initiated by splitting of $\mathrm{C} 5$ into $\mathrm{C} 5 \mathrm{a}$ and $\mathrm{C} 5 \mathrm{~b}$. Thus, C5a is formed during meconiuminduced complement activation, and it is reasonable to suggest that C5a may be important not only in accumulation of neutrophils in the lungs in MAS but also to their in situ activation.

Systemic inflammatory response syndrome is associated with procoagulant activity, complement activation, and cytokine release (37). In previous animal experiments with established MAS, there was a tendency of blood clotting obstructing aspiration for blood sampling. We assumed that this might be due to hypercoagulability developing in the course of MAS. In the same experiments, we observed a significant rise of IL-8 in tracheal aspirate of animals with established MAS as opposed to control animals (38). We therefore suggested a disseminated cascade activation in MAS. The present data on complement activation and cytokine release lend support to this hypothesis. Complement is suggested to play a pathogenic role in acute respiratory distress syndrome and septic shock (39). Our data show a systemic activation of complement early after instillation of meconium, preceding the rise in IL- $1 \beta$ and TNF- $\alpha$, suggesting that complement activation may be upstream of cytokine production. The local activation of complement in the lungs is most likely immediate after meconium instillation. This local inflammatory reaction seems to disseminate and lead to a systemic inflammatory reaction in which complement may play a pivotal role in initiating the systemic inflammation in MAS, possibly as a result of leakage of meconium from the lung to the systemic circulation (40). Of particular interest in this context was the observation of a very close correlation between the systemic complement activation reflected by plasma TCC and the mortality when subdividing the MAS group into survivors and nonsurvivors. Taken together, our data support the view that meconium per se is important for the inflammatory reaction in MAS.

\section{CONCLUSION}

This study has demonstrated complement activation and cytokine production in an experimental hypoxia-stressed piglet model of MAS. Complement activation as measured by TCC preceded the rise in cytokines. The increase in TCC correlated to deterioration in lung function as well as to mortality. Our data support the assumption that complement triggers early local and systemic inflammation in MAS and, thus, may be a possible target for future therapeutic intervention.

Acknowledgments. We thank Roger Ødegård for highly skilled technical assistance in surgery and Anne Pharo for excellent laboratory technical assistance. 


\section{REFERENCES}

1. Cleary GM, Wiswell TE 1998 Meconium-stained amniotic fluid and the meconium aspiration syndrome. An update. Pediatr Clin North Am 45:511-529

2. Wiswell TE, Tuggle JM, Turner BS 1990 Meconium aspiration syndrome: have we made a difference? Pediatrics 85:715-721

3. Brown CA, Desmond MM, Lindley JE, Moore J 1957 Meconium staining of the amniotic fluid; a marker of fetal hypoxia. Obstet Gynecol 9:91-103

4. Katz VL, Bowes WA Jr 1992 Meconium aspiration syndrome: reflections on a murky subject. Am J Obstet Gynecol 166:171-183

5. Bacsik RD 1977 Meconium aspiration syndrome. Pediatr Clin North Am 24:463-479

6. Wiswell TE, Bent RC 1993 Meconium staining and the meconium aspiration syndrome. Unresolved issues. Pediatr Clin North Am 40:955-981

7. Schulze M 1925 The significance of the passage of meconium during labor. Am J Obstet Gynecol 10:83-88

8. Co E, Vidyasagar D 1990 Meconium aspiration syndrome. Compr Ther 16:34-39

9. Holtzman RB, Banzhaf WC, Silver RK, Hageman JR 1989 Perinatal management of meconium staining of the amniotic fluid. Clin Perinatol 16:825-838

10. UK Collaborative ECMO Trail Group 1996 UK collaborative randomised trial of neonatal extracorporeal membrane oxygenation. Lancet 348:75-82

11. Carson BS, Losey RW, Bowes WA Jr, Simmons MA 1976 Combined obstetric and pediatric approach to prevent meconium aspiration syndrome. Am J Obstet Gynecol 126:712-715

12. Gregory GA, Gooding CA, Phibbs RH, Tooley WH 1974 Meconium aspiration in infants-a prospective study. J Pediatr 85:848-852

13. Wiswell TE, Gannon CM, Jacob J, Goldsmith L, Szyld E, Weiss K, Schutzman D, Cleary GM, Filipov P, Kurlat I, Caballero CL, Abassi S, Sprague D, Oltorf C, Padula M 2000 Delivery room management of the apparently vigorous meconium-stained neonate: results of the multicenter, international collaborative trial. Pediatrics 105:1-7

14. Wiswell TE 1992 Meconium aspiration syndrome made murkier. Am J Obstet Gynecol 167:1914-1916

15. Gooding CA, Gregory GA, Taber P, Wright RR 1971 An experimental model for the study of meconium aspiration of the newborn. Radiology 100:137-140

16. Terasaka D, Clark DA, Singh BN, Rokahr J 1986 Free fatty acids of human meconium. Biol Neonate 50:16-20

17. Clark DA, Nieman GF, Thompson JE, Paskanik AM, Rokhar JE, Bredenberg CE 1987 Surfactant displacement by meconium free fatty acids: an alternative explanation for atelectasis in meconium aspiration syndrome. J Pediatr 110:765-770

18. Schrama AJ, de Beaufort AJ, Sukul YR, Jansen SM, Poorthuis BJ, Berger HM 2001 Phospholipase A2 is present in meconium and inhibits the activity of pulmonary surfactant: an in vitro study. Acta Paediatr 90:412-416

19. Meis PJ, Hall M 3rd, Marshall JR, Hobel CJ 1978 Meconium passage: a new classification for risk assessment during labor. Am J Obstet Gynecol 131:509-513

20. Murphy JD, Vawter GF, Reid LM 1984 Pulmonary vascular disease in fatal meconium aspiration. J Pediatr 104:758-762

21. Tølløfsrud PA, Medbø S, Solås AB, Drevon CA, Saugstad OD 2002 Albumin mixed with meconium attenuates pulmonary dysfunction in a newborn piglet model with meconium aspiration. Pediatr Res 52:545-553
22. Lally KP, Mehall JR, Xue H, Thompson J 1999 Meconium stimulates a proinflammatory response in peritoneal macrophages: implications for meconium peritonitis. J Pediatr Surg 34:214-217

23. Kojima T, Hattori K, Fujiwara T, Sasai-Takedatsu M, Kobayashi Y 1994 Meconiuminduced lung injury mediated by activation of alveolar macrophages. Life Sci $54: 1559-1562$

24. Clark P, Duff P 1995 Inhibition of neutrophil oxidative burst and phagocytosis by meconium. Am J Obstet Gynecol 173:1301-1305

25. de Beaufort AJ, Pelikan DM, Elferink JG, Berger HM 1998 Effect of interleukin 8 in meconium on in-vitro neutrophil chemotaxis. Lancet 352:102-105

26. Soukka HR, Ahotupa M, Ruutu M, Kaapa PO 2002 Meconium stimulates neutrophil oxidative burst. Am J Perinatol 19:279-284

27. Mollnes TE, Song WC, Lambris JD 2002 Complement in inflammatory tissue damage and disease. Trends Immunol 23:61-64

28. Castellheim A, Lindenskov PHH, Pharo A, Fung M, Saugstad OD, Mollnes TE 2004 Meconium is a potent activator of complement in human serum and in piglets. Pediatr Res 55:310-318

29. Mollnes TE, Lea T, Harboe M, Tschopp J 1985 Monoclonal antibodies recognizing a neoantigen of poly $(\mathrm{C} 9)$ detect the human terminal complement complex in tissue and plasma. Scand J Immunol 22:183-195

30. Mollnes TE, Fosse E 1994 The complement system in trauma-related and ischemic tissue damage: a brief review. Shock 2:301-310

31. Clark RH, Gerstmann DR, Jobe AH, Moffitt ST, Slutsky AS, Yoder BA 2001 Lung injury in neonates: causes, strategies for prevention, and long-term consequences. J Pediatr 139:478-486

32. Korhonen K, Soukka H, Halkola L, Peuravuori H, Aho H, Pulkki K, Kero P, Kaapa PO 2003 Meconium induces only localized inflammatory lung injury in piglets. Pediatr Res 54:192-197

33. Holopainen R, Laine J, Halkola L, Aho H, Kaapa P 2001 Dexamethasone treatment attenuates pulmonary injury in piglet meconium aspiration. Pediatr Res 49:162-168

34. Tyler DC, Murphy J, Cheney FW 1978 Mechanical and chemical damage to lung tissue caused by meconium aspiration. Pediatrics 62:454-459

35. Davey AM, Becker JD, Davis JM 1993 Meconium aspiration syndrome: physiological and inflammatory changes in a newborn piglet model. Pediatr Pulmonol 16:101108

36. Tølløfsrud PA, Medbø S, Solås AB, Robertson B, Speer C, Seidenspinner S, Drevon CA, Saugstad OD 2004 Intratracheal albumin reduces interleukin-8 in tracheobronchial aspirates in piglets after meconium aspiration. J Perinat Med 32:78-83

37. de Boer JP, Wolbink GJ, Thijs LG, Baars JW, Wagstaff J, Hack CE 1992 Interplay of complement and cytokines in the pathogenesis of septic shock. Immunopharmacology $24: 135-148$

38. Lindenskov PH, Castellheim A, Aamodt G, Saugstad OD Meconium induced IL-8 production and lung injury may be alleviated by intratracheal albumin in ventilated piglets. Pediatr Res, in press

39. Ward P 2004 The dark side of C5a in sepsis. Nat Rev Immunol 4:133-142

40. Kearney MS 1999 Chronic intrauterine meconium aspiration causes fetal lung infarcts, lung rupture, and meconium embolism. Pediatr Dev Pathol 2:544-551 